ERIPIDOE Quarterly Report \#7 \& 8

\& Final report

April 1, 1999 through Sept. 30, 1999

A Pilot Plant Scale Reactor/Separator for Ethanol from Cellulosics

ERIP DOE Project DE-FG01-97EE15958

Bio-Process Innovation

226 N. 500 West

W. Lafayette, IN 47906-8505

Dr. M. Clark Dale, BPI, Project Director

Mark Moelhman, BPI, Lab Director

Rolf Butters, DOE/ERIP, Invention Coodinator

\title{
Project Aim
}

The objective of this project is to develop and demonstrate a continuous, low energy process for the conversion of cellulosics to ethanol. This process involves a pretreatment step followed by enzymatic breakdown of cellulose/hemicellulose and the consecutive simultaneous saccharification/fermentation (SSF) of cellulose (glucans) followed by hemicellulose (pentosans) in a multi-stage continuous stirred reactor separator (CSRS).

During the 7th and 8th quarters, we have focussed on tests of our steep delignification process for the pretreatment of maple hardwood shavings in particular, as we have a site, Berne Furniture in Ft. Wayne $\mathbf{I N}$, where a volume of these shavings are produced on a daily basis. We are also beginning to design and set-up our apparatus for the operation of the 130 Liter 6 stage pilot plant. We plan to run this system at our lab site on straw, and then as a followon process, either operate the $130 \mathrm{~L}$ or our $24,000 \mathrm{~L}$ unit at the Ft. Wayne IN site

During Q9-10 we will be running the $130 \mathrm{~L}$ process scale unit to demonstrate the process using straw. During Quarter 5 and 6, we acquired two $300 \mathrm{~L}$ stainless steel jacketed tanks for steeping delignification pilot operation, a regenerative blower for gas stripping ethanol separations from the pilot plant, four stainless steel $6^{\prime \prime}$ ID by $6^{\prime}$ colums for ethanol recovery operations, and a steel rack/ framework for the columns/ CSRS system. 


\section{DISCLAIMER}

This report was prepared as an account of work sponsored by an agency of the United States Government. Neither the United States Government nor any agency thereof, nor any of their employees, make any warranty, express or implied, or assumes any legal liability or responsibility for the accuracy, completeness, or usefuiness of any information, apparatus, product, or process disclosed, or represents that its use would not infringe privately owned rights. Reference herein to any specific commercial product, process, or service by trade name, trademark, manufacturer, or otherwise does not necessarily constitute or imply its endorsement, recommendation, or favoring by the United States Government or any agency thereof. The views and opinions of authors expressed herein do not necessarily state or reflect those of the United States Government or any agency thereof. 


\section{DISCLAIMER}

Portions of this document may be illegible in electronic image products. Images are produced from the best available original document. 


\section{Project Objectives}

There are three basic objectives to this ERIP project, 1) some basic research on co-production and/or recycling of cellulosic enzymes and development of pretreatment processing which allows enzymatic breakdown of the biomass 2) a lab scale development phase where the process is operated on a small scale, and process modeling, design, and economics, and finally, 3) a demonstration scale CSRS being built and operated.

\section{General Approach}

Cellulosics, or biomass sources, are a great internal renewable resource for fuels and chemicals for the USA. In this project, we will be using corn stover and straw as biomass sources to produce ethanol. Ethanol production from cellulose is currently hampered by several major difficulties, most notably 1) the difficulty in reducing biomass to fermentable sugars economically, and 2) the difficulty in fermenting xylans, or five carbon sugars which are the breakdown monomer of hemicellulose, which constitutes between 15 and $25 \%$ of most cellulosics. There are two basic methodolgies for breaking down cellulosics to constituent sugars, acid and enzymatic (cellulase) processes. In our work, we will be focussing on an enzymatic process which should require much milder $\mathrm{pH}$ 's and reduced capital costs. However, if enzymes are purchased, the enzyme cost alone can cause the biomass based ethanol to cost more than the current market price for ethanol.

The goals of this project are thus to make progress towards reducing three basic barriers to commercialization of biomass to ethanol via enzymatic hydrolysis, 1) co-production and/or recycling of cellulase (and hemicellulases) will be examined closely, 2) a low temperature/low pressure chemical/ chemical recycle process for biomass pretreatement, and 3 ) successive fermentation of cellulose/glucose followed by hemicellulose/xylose in a new bioreactor, the continuous stirred reactor/ separator (CSRS).

Ethanol production from cellulosics can be improved by various means:

1) Develop a high density of cells within the reactor so as to convert sugars to ethanol quickly

2) Combine enzymatic conversion of cellulose and hemi-cellulose polymers with fermentation so as to keep sugar levels low, improving enzymatic conversion rates

3) Convert both xylose and glucose to ethanol

4) Either co-produce crude cellulase enzyme or recycle the enzymes so as to reduce enzyme costs.

5) Separate ethanol from the reactor broth so as to keep reaction rates high 
A central effort of this project is to develop and demonstrate a continuous stirred reactor separator for the successive fermentation of xylans and glucans which will incorporate all the above design parameters improvements. Biomass generally consists of about $25-30 \%$ lignin, $25-30 \%$ hemicellulose, and $30-45 \%$ cellulose. The ideal process for biomass conversion to useful products must utilize each of these components. We are developing a delignification/pretreatment, followed by enzymatic release of xylans and glucans from the hemicellulose and cellulose respectively. Combining reaction (fermentation) with enzymatic release of sugars (Simultaneous Saccharification and Fermentation or SSF) improves the enzyme kinetics due to reduction of product inhibition. The basic process flows of the CSRS process for cellulose as we currently envisage it are shown in Figure 1.

\section{Progress Report}

This project is divided into three phases, 1) a basic phase consisting of laboratory studies on enzyme production, enzyme performance and enzyme recycling in cellulose breakdown, and pretreatment effectiveness, 2) a lab development stage consisting of operating batch bench scale saccharification fermentations (SSF) trials and 3 ) an applied or demonstration phase focusing on construction and operation of a $130 \mathrm{~L}$ or larger CSRS for the production of ethanol.

During quarters $7 \& 8$ have been focussing on

1) Improving our pretreatment so as to give good performance with hardwood shavings

2) Evaluating alternative chemicals for our pilot scale efforts

3) Continued designing and assembling 130 Liter pilot plant materials

1. Basic Research-The basic research is being performed at BPI's laboratory in W. Lafayette, IN.

Task 1. a) Cellulase/hemicellulase production and performance comparison- The enzymatic conversion of cellullose is often the rate limiting step during the simultaneous saccharification and fermentation. During quarters 1 and 2 , we demonstrated that recycled fermentation broth retained a high degree of enzymatic ability. Thus, our prelimary focus is now on recycling enzymes rather than the co-production in our upcoming pilot plant efforts. In the CSRS, temperatures stay low during the ethanol separation, so there is no destruction of the enzymes as would occur during a standard distillation process.

Co-production of enzymes however, would have a major beneficial effect on economics, so we will continue to pursue this line of research. We are obtaining strains of $T$. reesei from the NRRL. We currently are using a cellulase commercially available from Genecor for our work. 
b) Toxic effect of cellulase on yeast- Experiments performed during Q7 and Q8 indicated that the cellulase itself might be having a toxic effect on the yeast. At higher levels of use, (which were introduced based on poor performance or release of glucose at lower levels) glucose was released during SSF, but the yeast were not able to consume or metabolize the glucose. A series of experiments were performed to determine the effects of various levels of enzyme on yeast growth and fermentation. Two enzyme were tested Genencor $\mathrm{Cp}$ cellulase, and Genencor Ce cellulase.

$\mathrm{Cp}$ - Our experiments indicated that ethanol productivity begins to be inhibited at the $1 \%$ (g enzyme solution/g biomass) level, but that good cell growth was still noted. Cell growth was inhibited at $2 \%$ enzyme addition, and both cell growth and ethanol productivity severly inhibited at $4 \%$.

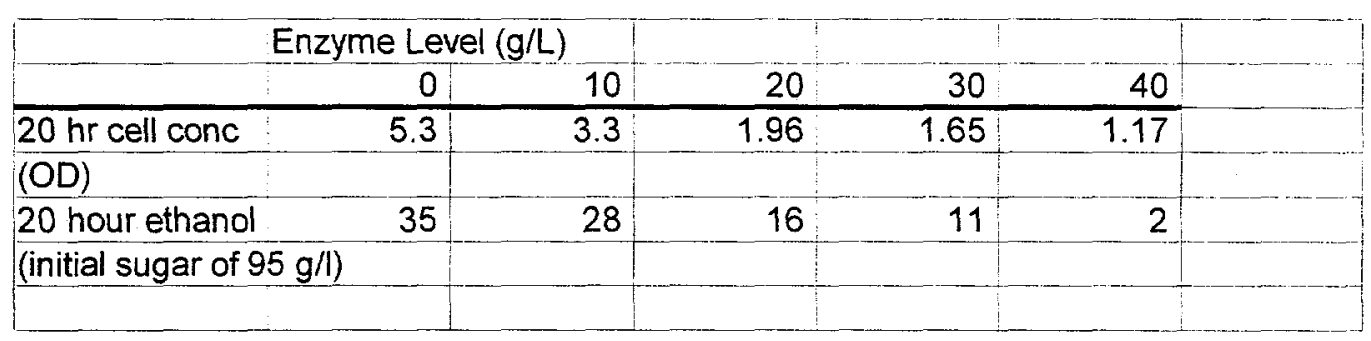

Ce- A similar inhibition pattern was noted with this enzyme, but less severe inhibition was noted at the $4 \%$ level of enzyme.

In direct SSF comparisons, Cp cellulase gave a faster fermentation with higher final ethanol concentrations and better biomass conversion than the $\mathrm{Ce}$ product. 
Figure 2.

\section{Straw SSF w/ Different Enzymes}

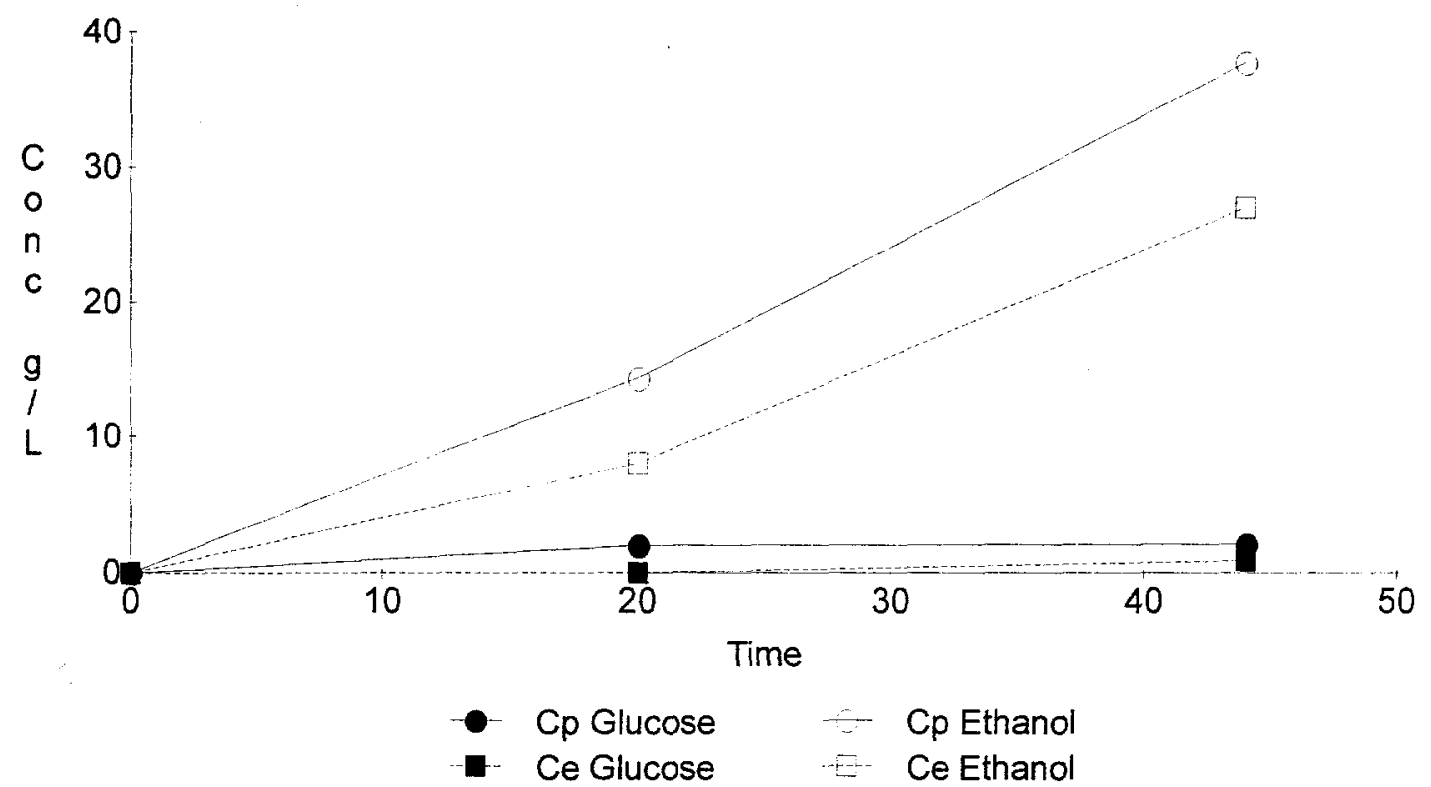

As seen in this figure, the Cp enzyme released more glucose, and allowed more ethanol to be formed. The slightly more inhibitory nature of the $\mathrm{Cp}$ may have led to the presence of residual glucose at both 20 and 44 hours.

c) pretreatment of maple shavings

Our major effort during Q7 and Q8 have focussed on improvements in BPI's proprietary pretreatment system. Our goal is to develop a process which allows recycling of chemicals, and does not result in the production of toxic byproducts which would inhibit the fermentation process. We have established a relationship with a furniture manufacturing company, who are interested in siting a pilot scale biomass to ethanol project. The biomass produced by this company consists of hardwood shavings, largely maple. Our pretreatment process which has been developed and tested on straw biomass, showed only $50 \%$ utilization of the biomass on the maple.

Process variables which we have evaluated over the last two quarters to improve pretreatment performance on maple include:

1) physical agitation

2) temperature

3) nutrient additions

4) pressure

5) time duration of treatments

6) aeration of fermentation broth

7) enzyme concentration

8) chemical levels

9) liquid to mass ratios 
Eight different pretreatment trials were performed during April through August. Higher temperatures and higher pressures were not found to promote the delignification process. Physical agitation was found to be the most effective aid in promoting both delignification and fermentability/degradability by enzymes.

\subsection{Pilot/ Demonstration Scale CSRS}

During quarter 8 , we have begun some studies using a non-volatile base versus a volatile base. A volatile base will allow recycling of the base and is the pretreatment chemical of choice for our process. We have also had some indications in our previous trials that pressurizing the steep process helped improve the delignification process. However, for the purpose of our initial pilot scale trials, simplicity and lack of chemical hazard is more important. Thus, we have been evaluating the performance of a non-volatile base in our steep as well as non-pressurized conditions. The effects of agitation versus steeping has also been evaluated during quarter 8 .

\section{Pressure/ Non-Volatile base effect on Delignification performance}

In a recent series of experiments, low temperature steeping of straw using a non-volatile base showed $38 \%$ solubilization (indicating excellent delignification....our highest solubilization levels to date are $41 \%$ ) versus $33 \%$ with our volatile base $\mathrm{w} /$ pressure, and $35 \%$ solubilizaton with the volatile base w/o pressure. These results led us to move towards use of the non-volatile base w/o pressure. Conditions which will allow us to operate the pilot plant in our lab, as opposed to operating outdoors if conditions were more severe.

\section{Agitation/ Non-Volatile base}

Using rapid stirring with the NVB, (Exp \# NVB-PTR-1), we noted excellent pulping of straw in 24 hours, versus steep delignification requiring 72 hours. We noted $38 \%$ solubilization of the straw in 24 hours. These results indicate that size of equipment can be reduced if agitation is added to the delignification process.

\section{Effect of Non Volatile Base on SSF Performance}

The question of whether ther NVB would adversely affect the fermention was next addressed. Two experiments were performed:

1) rinsing the base prior to $\mathrm{pH}$ neutralization,

Exp \# NVB-SSF-1, $0.8 \mathrm{ml}$ cellulase- little liquifaction of biomass in 24 hours... add another $0.5 \mathrm{ml}$ - good performance, $80 \%$ conversion of solids to sugars/ethanol 
Exp \#NVB-SSF-2. $1 \mathrm{ml}$ cellulase gave good conversion as seen in Figure 1 , with $88 \%$ of the solids converted to soluble sugars or ethanol $(12 \%$ recovered as solids recovered by filtering through cotton 'duck' cloth.

Figure 1. SSF of NVB treated Straw- $24 \mathrm{hr}$ pretreatment

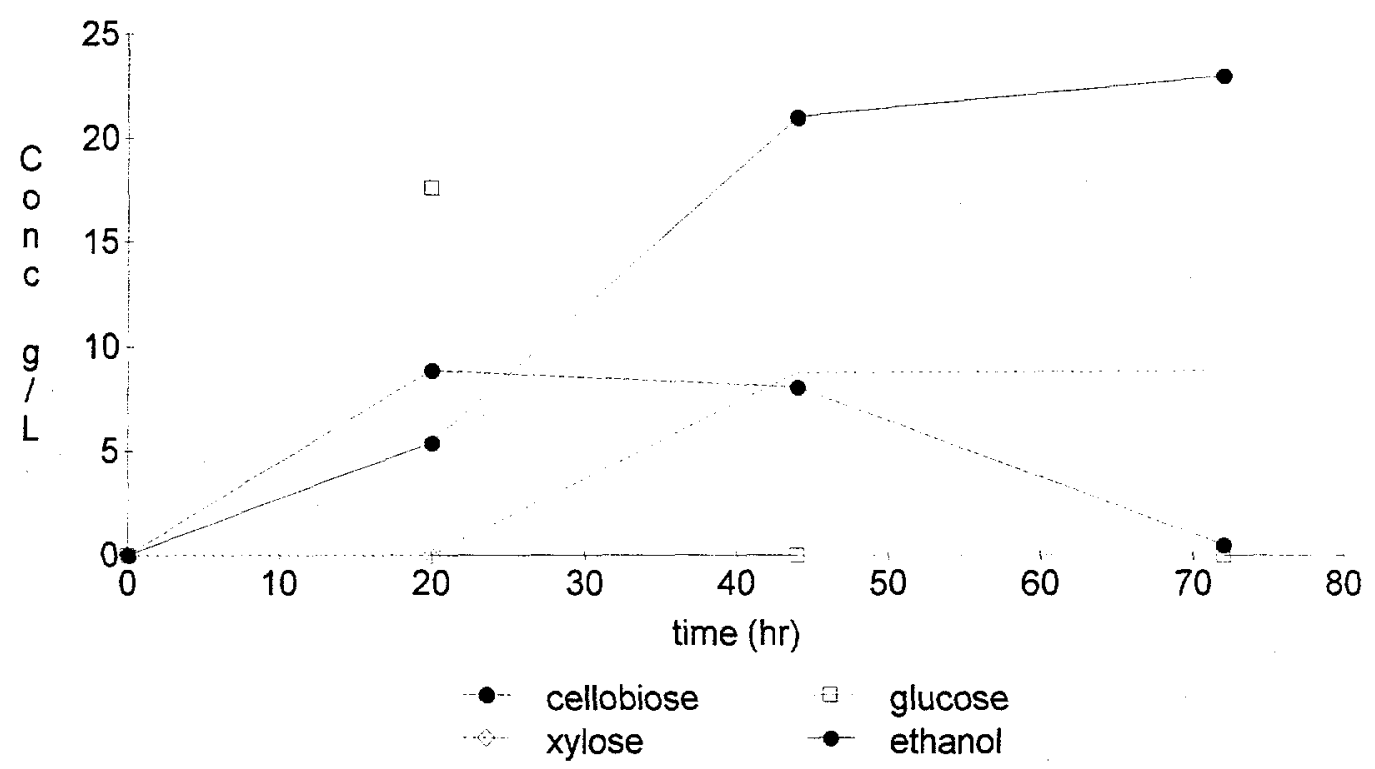

2) neutralization w/o rinsing. In Exp. \#NVB-SSF-4, the pulp from Exp \# NVBPTR- 1 was fermented with $1 \mathrm{ml}$ cellulase. Similar results to Figure 1 were noted, with $20 \mathrm{~g} / \mathrm{L}$ ethanol reached in 48 hours, and $85 \%$ of the biomass solubilized/converted. Thus, the amount of NVB remaining in the broth is not particularly inhibitory to the fermentation.

3) Experiments with and without auxilary 'pulping' compounds. In Experiment \#NVB-SSF-2, the pretreatment was run without a second pulping compound. We observed that a good 'pulp' was created within 24 hours, $30 \%$ solulbilization of the original biomass, and some visual lack of breakdown on the straw structure. This biomass was then fermented in Exp \# NVB-SSF-3, where $22 \mathrm{~g} / \mathrm{L}$ ethanol was reached in 48 hours, (similar to previous experiments) but only $63 \%$ of the biomass was solublized.

These results indicate that the auxilary pulping compound is important with the NVB. $\quad$ Using our volatile base without the pulping compound in Exp. \# VBPRT-3, we noted only $18 \%$ of biomass solubilized in 24 hours, indicating the pulping compound is more crucial to the volatile base pretreatment 4) Conclusions from work to date $w / N V B$ and agitation.

a) Good pulping in 24 hours versus 72 hours

b) SSF performance not as good as with VB and pulping adjuncts

c) need to work on improving pretreatment so as to improve final ethanol concentrations in the range of $35-42 \mathrm{~g} / \mathrm{l}$ as obtained on straw. 